\title{
Contribuição para 0 estudo dendrológico de cinco leguminosas da Amazônia
}

\author{
ARTHUR A. LOUREIRo( $\left.{ }^{*}\right)$ \\ Marlene Freitas da Silva $(*)$ \\ Instituto Nacional de Pesquisas \\ da Amazônia
}

\begin{abstract}
SINOPSE
Cinco leguminosas da Amazônia são referidas: Lecointea amazonica, Macrolobium acaciaefolium, Hymenaea parvifolia, Crudia amazenica e Dimorphandra parviflora. Para cada espécie são apresen. tadas as seguintes indicações : a) da árvore - descrição botânica, habitat, ocorrência geográfica e no. mes vulgares; b) - da madeira - caracteres gerais, descrição macro e microscópica, e usos comuns. Ilustram o trabalho 5 macros e 10 microfotografias do lenho das referidas espécies.
\end{abstract}

\section{INTRODUÇÃo}

$O$ presente trabalho refere-se como o que o precedeu, ao estudo dendrológico de cinco espécies euxilóforas da Amazônia, todas pertencentes à familia das leguminosas, importantes não só do ponto de vista da utilidade industrial de suas madeiras, como pela beleza que emprestam ao habitat onde se encontram.

\section{MATERIAL CONSULTADO}

O material botânico e xilológico estudado encontra-se registrado e arquivado no Herbário e Xiloteca do INPA, em particular, alguns exemplares com amostras nos Herbários do IAN, MG, NY, US, K, S, F, U, A, R, P, M, MICH, C, G. MO, COL, e VEN, com os seguintes dados de coleta :

\section{1 - Hymenaeae parvifolia}

BRASIL - Est. Amazonas : Manaus, Reserva Florestal Ducke; mata de baixio, solo argiloso; fr.; J. Aluizio 295, em 25.6.969 (INPA 27.476). Ibid.; mata de t. fir- me; fr.; J. H. Langenheim \& W. Rodrigues, 5618, em 2.10.969 (INPA 27.662). Manaus, estr. Manaus-Itacoatiara, km 70 , mata de t. firme, solo argiloso; fr.; W. Rodrigues, Coêlho 1879, em 27.10.960 (INPA 8251; X-813); Serra near Namorado Novo between rio Curuquetê, rio Madeira, Abunā; fr.; G. T. Prance et al. 14.713, em 5.8.971 (INPA 32.928). State of Pand. W. bank of rio Madeira, opposite Abunã; forest on terra firme; fr.; G. T. Prance et al. 5806, em 10.7.968 (INPA 22.563). X-3630. Est. Maranhão: Estação Experimental Florestal. Turi; fl.; leg.(?), em 3.11.967 (INPA 20.841). Araguanã, alto Turi; W. Rodrigues 8260 , em 28.9.966 (INPA 17.650).

T. Rondônia: Estr. Porto Velho-Cuiabá, $\mathrm{km} \mathrm{117}$; forest on $\mathrm{t}$. firme; fr.; G. T. Prance \& J. F. Ramos 6987, em 15.8.968 (INPA 23.746).

T. Roraima: Canta Galo, rio Mucajaí, entre Pratinha e rio Apiau; mata de t. firme; fr.; G. T. Prance et al. 3951, em 21.1.967 (INPA, 19.592).

\section{2 - Crudia amazonica}

ERASIL - Est. Amazonas : Manaus, ig. da Cachoeira Baixa do Tarumã; igapó: $\mathrm{fr}$. jovens; $W$. Rodrigues $\mathrm{s} / \mathrm{n} .{ }^{\circ}$, em 22.6.955 (INPA 1236). Município de Silves; várzea; fr.; W. Rodrigues 262 , em 28.11.956 (INPA 4372). Município de Manacapuru, Estirão do Mucumiri; igapó de água preta; fr.; W. Rodrigues

(•) Bolsista do Conselho Nacional de Pesquisas. 
375, s/data (INPA 5254). Rio Negro, rio Sumaúma; igapó; fr.; L. Coêlho s/n. ${ }^{\circ}$, em 6.4.959 (INPA 7286). Lago do Janauari; igapó; fr.; W. Rodrigues, J. Lima 2480, em 5.5.961 (INPA 8986; X-930). Ibid.; igapó; fr. jovens; W. Rodrgiues \& D. Coêlho 2504, em 5.5.961 (INPA 9010; X-939). Ibid.; margem inundável do lago; fr.; A. Loureiro \& F. Mello $\mathrm{s} / \mathrm{n} .^{\circ}$, em 12.9.963 (INPA 14.140; X-2025). Município de Maués, Limão-Limoeiro; igapó; fr.; W. Rodri. gues, L. Coêlho 7713, em 18.4.966 (INPA 17.018). Paraná do Autaz-Mirim; t. argiloso sujeito a inundação temporária; fr.; W. Rodrigues \& F. Mello 7.782, em 21.4.966 (INPA 17.088; X-3515). Rio Negro, lago do Paracuuba; fr.; L. Coêlho $\mathrm{s} / \mathrm{n} .^{\circ}$, março de 1969 (INPA 27.330) Rio Solimões, lago do Janauaca, Italiano; fl. e fr. jovens; Byron 153, em 4.7.969 (INPA 27.405; X-4050). Manaus, km 14 da estrada do Aleixo, Porto Mauá; igapó; fr. jovens; W. Rodrigues 8.847 , em 23.4.970 (INPA 28.0602).

Est. Pará: R. L. Fróes 23.332 s/ data; fr. jovens; (INPA 6595).

T. Fed. Rondônia: Baixo rio Madeira, rio Jaciparaná; mata em terreno inundável; fr. G. T. Prance 5293, em em 28.6.968 (INPA 22.053).

\section{3 - Dimorphandra parviflora}

BRASIL-Est. Amazonas: Manaus, igarapé do Buião; mata de t. firme, solo argiloso; fl.; W. Rodrigues, s/n. ${ }^{\circ}$, em 7.7.955 (INPA 1344; X-188). Manaus, estr. BR-17, km 13; fl.; L. Coêlho \& F. Mello s/n. ${ }^{\circ}$ em 14.4.956 (INPA 3747). Manaus, igarapé do Bindá; capoeira t. firme, solo argiloso; $\mathrm{fl}$; Dionizio $\mathrm{s} / \mathrm{n}$. em 26.4.956 (INPA 3787). Manaus, Reserva Florestal Ducke; mata de t. firme, solo argiloso; W. Rodrigues, A. Loureiro, 5921, em 19.6.964 (INPA 14865; X - 2854). Ibid.; fr.; W. Rodri gues \& L. Coêlho 8575, em 4.10.968 (INPA 21.543). Município de Tefé, Est. Exp. do IAN; W. Rodrigues \& L. Coêlho 1435, em 28.11.959 (INPA 7766).

\section{4 - Macrolobium acaciaefolium}

BRASIL-Est. Amazonas: Manaus, km 64 da Estr. Manaus-Itacoatiara; fr.; Byron \& D. Coêlho 127, em 2.2.969 (INPA 25.917). Município de Manacapuru, Estirão do Mucumiri; igapó de água preta; fr.; W. Rodrigues 373 , s/ data (INPA 5₹.57). Município de Maués, Prainha, margem alagável do rio; fr.; W. Rodrigues \& L. Coêlho $6776, \mathrm{~s} /$ data (INPA 15.240). Paraná do Autaz-Mirim. próximo de Manaus, terreno argiloso sujeito a inundação temporária; fr.; W. Rodrigues \& F. Mello 7789, em 22.4.966 (INPA 17.092; X-3519). Lago do Janauari, margem inundável do lago; fl. e fr.; A. Loureiro \& F. Mello $\mathrm{s} / \mathrm{n} .^{\circ}$, em 12.9.960 (INPA 28.096; X 4108). Puraquequara, ig. do Canaimã; igapó; fr.; W. Rodrigues \& D. Coêlho 5275, em 7.6.963 (INPA 13.943; X1921). Manaus, Cacau Pirera; igapó; fr.; W. Rodrigues \& L. Coêlho 2573. em 3.10.961 (INPA 9922). Rio Sumaúma; igapó; fr.; L. Coêlho $\mathrm{s} / \mathrm{n} \stackrel{\circ}{ }^{\circ}$, em 5.4.959 (INPA 7285). Rio Janauari, margem do rio; fl.; Corner 8 , em agosto, 1948 (iNPA 6668). Rio Purus, lago da Cobra; fr.; G. T. Prance et al. 2421. em 19.9.966 (INPA 17.963, NY). Lago do Janauari; igapó; fr.; W. Rodrigues, D. Coêlho 2507, em 5.5.961 (INPA 9013; X-940!. Ibid.; igapó; fr.; W. Rodrigues et al. 2707, em 2.6.961 (INPA $9250 \times$-985). Ibid.; margem do lago sujeito a inundação periódica; fl.; $\mathrm{A}$. Loureiro \& F. Mello s/n ${ }^{\text {, em } 12.9 .960}$ (INPA 14.138; X-2023).

Est. Pará: Rio Arari. Ilha de Marajó, Faz. Tuiuiu, margem do rio; fl.; G. A. Black, et al. 14.315, em 28.4.952 (INPA 4884, IAN).

T. Fed. Amapá: Aporema, Campo Belo, mata da beira do rio e campos alagados; fl. e fr.; W. A. Egler 666, em 31.10.967 (INPA 12.024, MG).

T. Fed. Rondônia: Rio Jaciparaná, terreno periodicamente inundável; $\mathrm{fl}$. e fr. jovens; G. T. Prance et al. 5301. em 28.6.968 (INPA 22.061, NY, US, 
K, S, MG, F, U, A, R, P, M, MICH, C, G, MO, COL, VEN). Rio Ribeirão, margem arenosa; fr.; G. T. Prance et al. 6577, em 27.7.968 (INPA 23.335, ibid.).

T. Fed. Roraima: Rio Uraricoera; margem do rio; fr.; G. T. Prance et al. 10.707, em 26.2.971 (INPA 29.059, NY). Rio Mucajaí, margem do rio; fr.; G. T. Prance et al. 11.096, em 18.3.971 (INPA 29.497).

\section{5 - Lecointea amazonica}

BRASIL - Est. Amazonas: Margem do Paraná do Autaz-Mirim; t. argiloso, sujeito a inundação temporária; fr.; F.. Mello 15, em 11.5.966 (INPA 17.164; X 3743). Ibid.; fr.; W. Rodrigues \& F. Mello 7768, em 19.4.966 (INPA 17.074; $X$ - 3501). Canal do Capitari; t. sujeito inundação temporária; W. Rodrigues \& F. Mello 7751, em 15.4.966 (INPA 17.057; X-3.486). X-2013.

\section{MÉTodo}

Como nos trabalhos anteriores, a descrição botânica das espécies foi baseada em material herborizado, seguramente identificado, confrontando os seus caracteres morfológicos com a descrição original dos autores das espécies estudadas, acrescida de algumas particularidades que muito podem auxiliar na identificação das referidas espécies. A distribuição geográfica, 0 habitat, e os nomes vulgares adotados nos diferentes locais, foram concluídos dos diversos trabalhos e material de herbário consultados.

Para as lâminas, os corpos de prova foram retirados da parte mais externa tanto do cerne e. também do alburno, que é a camada composta de elementos celulares ativos. Para obtenção dos cortes em micrótomo, impregnamos o lenho com parafina, a fim de evitar a dilaceração ou ruptura dos seus elementos constituintes. Em seguida, feitos alguns cortes transversalmente ao eixo da árvore, e os outros no sentido longitudinal: perpendicularmente aos raios (tangencial) e paralelamente a estes (radial) em micrótomo Jung $R$. Jungag, utilizando sempre a técnica comum, dividindo os cortes em três tipos: uns permanecem na cor natural, outros coloridos pela safranina hidroalcoólica e os Jemais pela hematoxilina de Delafield e, por fim, montados em bálsamo do canadá entre lâmina e lamínula.

A terminologia usada para a descrição anatômica segue Milanez \& Bastos (1960), e a avaliação das grandezas obedece as normas de Chattaway (1932).

Para maceração retiramos algumas lascas da parte mais interna do alburno, submergindoas em solução de ácido nitrico a $50 \%$. Para tornar rápida a solução do $\mathrm{HNO} 3$, aquecemo-lo em um tubo de ensaio durante alguns minutos. Alcançando o limite ideal para a decomposição dos elementos constituintes da madeira, lavamos em água destilada e coramos em safranina hidroalcoólica. Após a coloração e nova lavagem, foi dissociado sobre lâmina em uma gota de glicerina com auxílio de agulha histológica e lupa Olympus. Em seguida, procedemos a montagem e lutagem das lâminas para as devidas mensurações.

Para cada espécie foram feitas medições de 100 fibras, além de 30 para espessura da parede, outro tanto para diâmetro do lúmen e cerca de 45 para elementos vasculares.

Hymenaea parvifolia Hub. in Bul. Mus. Goeldl VI : 209 (1910).

- Hymenaeae pororoca Hub. nomem nudum.

\section{Nomes vulgares:}

RRASIL - Est. Amazonas: Jutaí mirim (Manaus, INPA 27.476)

Est. Pará: Jutaí (Cacual Grande); Jutai pequeno (Monte Alegre); Comer-de-arara (Almeirim), Le Cointe (1957); Jutaí pororoca (Belém, Bragança e Óbidos, seg. Ducke (1949).

Est. Maranhão: Jutaí mirim, J. curuba Araguanã), Jatobá curuba (Turi).

T. Fed. Roraima: Jutaí (Canta Galo. rio Mucajaí). 


\section{Caracteres botânicos}

Como as demais espécies do gênero, os indivíduos assim denominados são regularmente árvores de grande porte, 20 (30) metros de altura, de fuste ereto, cilindrico e bastante volumoso. Seg. Ducke (1949) também encontrase "indivíduos pequenos (mesmo arbustivos) no capoeirão e em certos campos cobertos". Fothas compostas de 2 folíolos, pequenos em relação as demais espécies, falcato-acuminados, glabros, fortemente coriáceos, não reticulados, vernicosos na face superior, na inferior opacos. Flores pequenas em inflorescências terminais densas; cálice tomento-acinzentado ou gríseotomentoso externamente; pétalas densamente pilosas internamente; ovário totalmente revestido de longos pelos brancacentos. Frutos indeiscentes, relativamente pequenos, de forma ovóide, às vezes ligeiramente comprimidos, contendo 1 (2) sementes. Afirma Le Cointe (1947), que a resina que exuda da casca "jutaicica", dissolvida em xilol substitui o bálsamo do canadá nas preparações microscópicas.

\section{Habitat :}

Mata da terra firme de solo arenoso ou argiloso "capoeiras e a beira de certos cerrados (Monte Alegre, no baixo Amazonas)" seg Ducke (1935).

\section{Gcorrência geográfica :}

Ocorre com mais freqüência no Estado do Pará do que no Amazonas, chegando até o Estado dc Maranhão, Territórios de Rondônia e Roraima.

\section{DADOS GERAIS SÔBRE A MADEIRA}

CARACTERÍSTICAS GERAIS :

Madeira muito pesada $\left(0,95-1,00 \mathrm{~g} / \mathrm{cm}^{3}\right)$ : cerne marrom a castanho avermelhado com algumas manchas irregulares enegrecidas, bem diferenciado do alburno creme; odor desagra. dável, gosto não pronunciado; grã regular; textura média a um tanto grosseira; superfície pouco lustrosa no alburno. Difícil de trabalhar devido a pequenas concreções resinosas que prejudicam consideravelmente a ferramenta. Madeira dura, incorruptível.
DESCRIÇÃO MACROSCÓPICA :

Parênquima relativamente abundante, apenas visivel a olho nu, em linhas concêntricas pouco onduladas, apresentando uma distribuição uniforme na largura e espaçamento; às vezes observa-se algumas associadas, ainda aliforme de aletas muito curtas e vasicêntrico. Poros de pouco a poucos numerosos, apenas visiveis a olho desarmado, solitários predominantes, múltiplos de 2 - 3 ; de pequenos a médios, vazios ou excepcionalmente obstruídos. Linhas vasculares bem visiveis sem ajuda de lente, são retas, contendo substâncias da cor do lenho. Raios praticamente de dois tipos, os mais grossos apenas visíveis a olho nu, os finos só com auxílio de lente; no sentido perpendicularmente aos raios (tangencial) são irregularmente distribuídos e paralelamente a estes (radial) bem perceptíveis a simples vista. Camadas de crescimento distintas, demarcadas por zonas mais escuras de tecido fibroso e também pelos canais secretores. Máculas medulares não foram observadas. Canais secretores longitudinais presentes, associados na linha do parênquima, observados a olho nu.

DESCRIÇÃO MICROSCÓPICA :

Vasos de secção ovalada a circular, parede grossa, em média de $6-20 \mu$, distribuição uniforme; médios a grandes, entre $130-240 \mu$ de diâmetro tangencial, maioria de $160-220 \mu$ $(50 \%)$; vazios; de muito pouco a poucos, 2 - 6 por $\mathrm{mm}^{2}$, com predominância de $4-6$, excepcionalmente encontrando-se campo com apenas 1 vaso por $\mathrm{mm}^{2}$; solitários predominantes $(85 \%)$ e múltiplos de 2-3; placas de perfurações simples; pontuações intervasculares areoladas. disposição alterna, inclusa, em média apresenta $6 \mu$; elementos vasculares de muito curtos a longos com uma variação de $210-600 \mu$ de comprimento, mais freqüente entre $250-450$, alguns com apêndice curto de um lado. Raios irregularmente dispostos, heterocelulares; multisseriados, predominando os raios de $4-5$ células de largura $(84 \%)$, raros de 3 - 6 células $(13 \%)$, ocasionalmente uni e bisseriados; de extremamente baixos a muito baixos de $190-1000 \mu$ de altura, maioria entre 310-900 $(81 \%)$, excepcionalmente encontra-se de $140 \mathrm{e}$ 
Hymenaeae parvifolia Huber

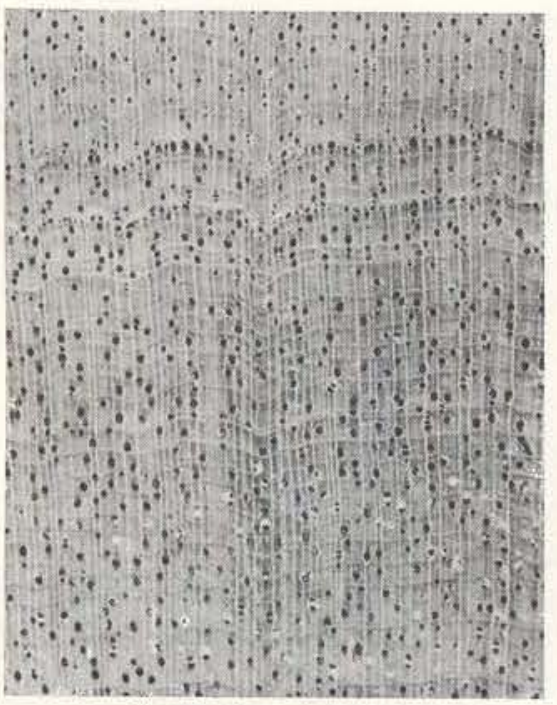

Corte transversal $(5 \mathrm{x})$
2

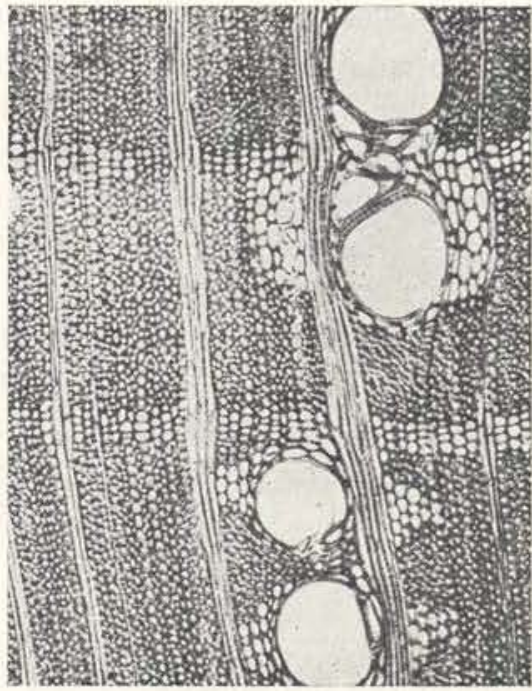

Corte transversal $(80 \mathrm{x})$

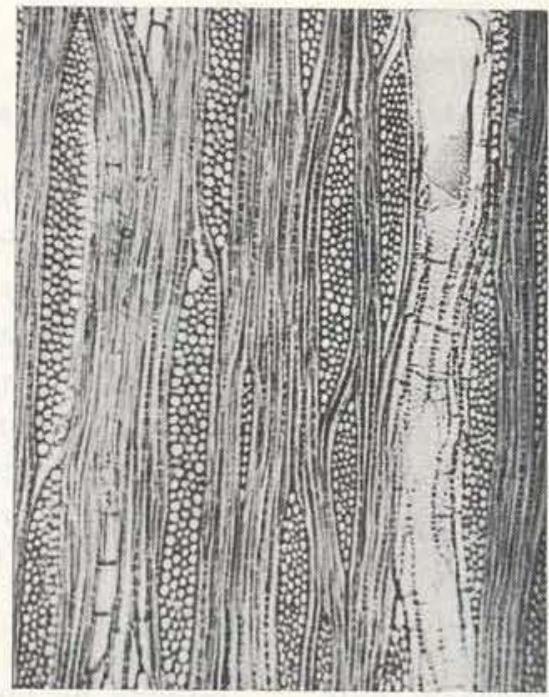

Corte tangencial $(60 \mathrm{x})$ 
até $1.780 \mu$; altura em número de células vai de 6 - 97, predominando os raios de 21 - 50 células $(70 \%)$; número de raios por milímetro linear $4-8$, com maior freqüência de $5-6$ raios $(78 \%)$. Cristais abundantes, grandes, às vezes em longas séries hemicristalíferas e holocristaliferas, margeando um lado dos raios; pontuaçc̄es radiovasculares, em média de $6-9 \mu$. Parênquima axial lembrando o apotraqueal terminal em nítidas faixas afastadas de $2-6$ células de largura, com predominância de 4 - 5 células, também paratraqueal unilateral, aliforme de aletas curtas e vasicêntrico. Fibras de pontuações simples, espessura da parede $3 \mu$, diâmetro do lúmen varia de 9-12 $\mu$; elementos fibrosos de muito curtos a curtos $870-1.150 \mu$ de comprimento. Camadas de crescimento distintas ou freqüentemente duvidosas, demarcadas por tecido fibroso, pelas faixas de parênquima e também delimitadas pelos canais secretores.

\section{USOS COMUNS :}

Dormentes, construções pesadas, cabos de ferramentas, obras hidráulicas.

Crudia amazônica Sp̣r. ex Bth. in Mart. Fl. Bras. XV. II :238.

Nomes vulgares:

BRASIL - Est. Amazonas: Orelha de cachorro (Manaus), Lombrigueiro*, (Silves e, provavelmente, em outras regiões do interior do Estado).

Est. Pará : Faveira do igapó (Rio Tapajós), Le Cointe (1947). Conhecida ainda seg. Record \& Hess (1943) pelos nomes : ipê, iperana, jutahyrana.

\section{Caracteres botânicos:}

Árvore bastante esgalhada, não excedendo a $15 \mathrm{~m}$ de altura, freqüentemente de porte não identificado, devido o seu habitat, mantendo apenas as extremidades dos ramos acima do nivel das áquas. Distinta e reconhecível mesmo a distância na época da frutificação, pelo aspecto original de seus frutos castanho ama- relados pendendo das extremidades dos ramos. Inflorescência racemosa com flores cremes (INPA 27.405), pouco aromáticas; pétalas efêmeras, ovário densamente piloso. Fruto, legume plano, levemente reticulado - venoso, densamente piloso; pelos sedosos, amarelo ferrugíneos.

Habitat :

Freqüente nas margens alagáveis dos rios e lagos de solo arenoso ou areno-argiloso.

Ocorrência geográfica :

Ocorre nos Estados: Amazonas: Manaus e localidades próximas; Rio Negro; Rio Solimões e Baixo Madeira.

Pará: seg. Ducke (1949), Almeirim, rios da região da Velha Pobre; Santarém; Óbidos, Lago do Curumu, margem do baixo Trombetas (freqüente) e do baixo e médio Tapajós.

\section{DADOS GERAIS SOBRE A MADEIRA}

CARACTERÍSTICAS GERAIS :

Madeira muito pesada $\left(0,90-1,00 \mathrm{~g} / \mathrm{cm}^{3}\right)$; cerne castanho, alburno creme; insípida e inodora; grã regular para revessa; textura fina para média. Difícil de trabalhar, recebe lustre me diano.

\section{DESCRIÇÃO MACROSCÓPICA :}

Parênquima abundante, contrastado, visive! ou até mesmo distinto a olho nu, em faixas ou linhas largas regularmente distribuidas, aproximadas, pouco onduladas, concêntricas, às vezes interrompidas, ligando e envolvendo os poros. Poros visíveis sob lente, pequenos a médios, poucos, solitários predominantes, múl tiplos de 2, raros de 3 , vazios, alguns obstruídos. Linhas vasculares perceptiveis a simples vista, longas e retas Raios no topo são finos e numerosos, apresentando uma certa uniformidade na largura e espaçamento, na face tangencial são irregularmente dispostos, na radial

(*) Em Silves, Município do Est. do Amazonas, a casca da árvore é usada como vermífugo poderoso, dai o nome pelo qual é vulgarmente conhecido "Lombrigueiro". 
Crudia amazonica Spr. ex Benth

4

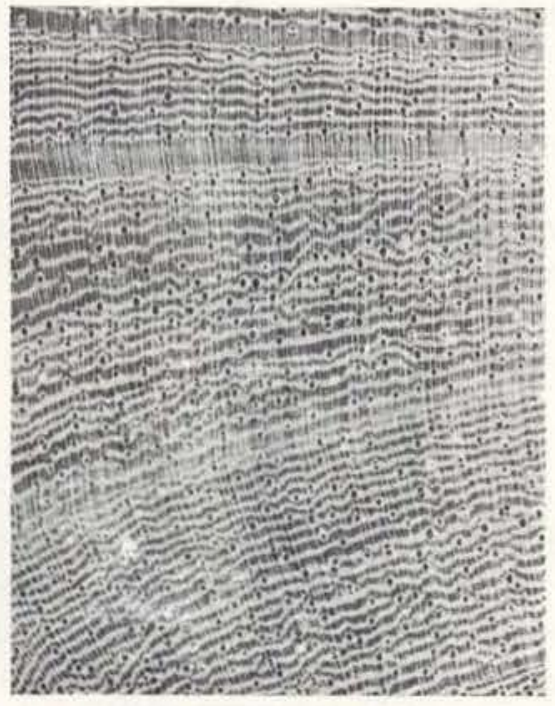

(Corte transversal $(5 \mathrm{x})$
5

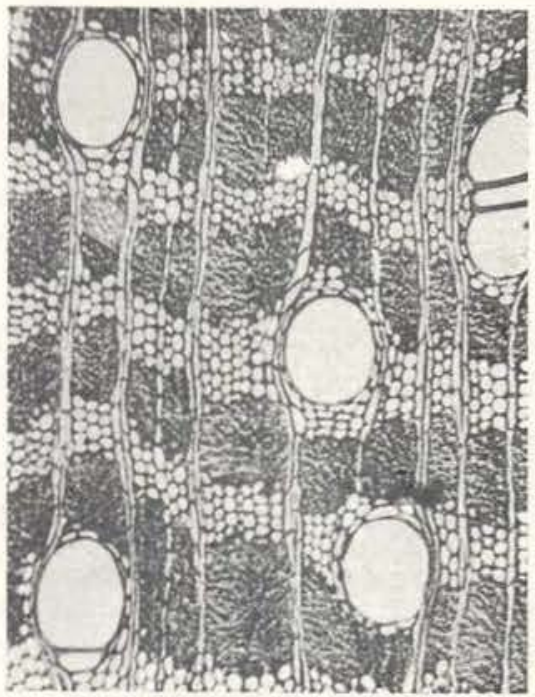

Corte transversal ( $80 \mathrm{x}$ )

6

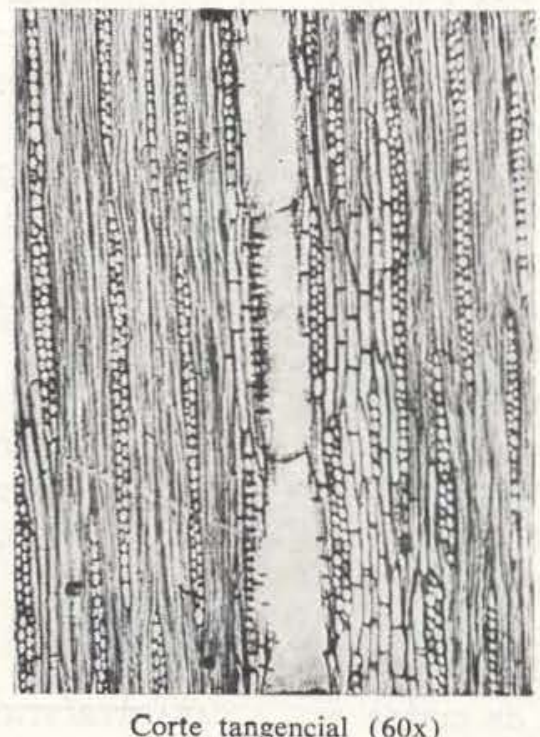


são contrastados. Camadas de crescimento demarcadas por zonas fibrosas mais escuras sem presença de parênquima e alguns campos com ausência de poros. Máculas medulares e canais secretores não identificados.

IESCRIÇÃO MICROSCÓPICA :

Vasos distribuição difusa, secção oval, raras vezes circular, parede grossa com 6-20 $\mu$ de espessura; médios a grandes, variando de $110-210 \mu$ de diâmetro tangencial, predominando os de $160-210 \mu(59 \%)$, de $100-150 \mu(41 \%)$; totalmente vazios; de muito pouco a pouco numerosos, $2-7$ por $\mathrm{mm}^{2}$, sendo a maior freqüência de 4-5-6; solitários predominantes $(67 \%)$, múltiplos de $2(23 \%)$, alguns de 3 , excepcionalmente até 4; placas de perfurações simples, pontuações intervasculares pequenas, $3 \mu$, areoladas, disposição alterna, abertura inclusa; elementos vasculares de muito curto a curtos, medindo de 300 a $360 \mu$ de comprimento, sem presença de apêndice, ou excepcionalmente com um apêndice em um dos extremos. Raios heterogêneos, irregulares, multisseriados, geralmente de 1 - 3 células de largura. predominando os bisseriados com $(68 \%)$ e trisseriados com $(22 \%)$, os unisseriados com apenas $(10 \%)$; altura em número de células vai de $7-37$, ocasionalmente de 4-40; de extremamente baixos a muitos baixos $250-800 \mu$ de altura, esporadicamente de 150-200 $\mu$; número de raios por milimetro linear de 6-11, ocasionalmente de 4-13, mais freqüente de $7-10(81 \%)$, encontrando-se também raios funsionados numa média de $25-30 \%$ da totalidade, de muito baixos a baixos $550-1.500 \mu$ de altura e com 25 - 65 células; pontuações radiovasculares do mesmo tipo das intervasculares, em média $3 \mu$. Parênquima axial abundante, paratraqueal, confluente, formando faixas regulares para irregulares, aproximadas, pouco onduladas, ligando os poros com uma largura de 2 - 8 células, mais freqüente de 4 - 5 células; cristais presentes em séries merocristalíferas a holocristalíferas, muito freqũente no corte radial. Fibras de pontuações simples, diâmetro do lúmen de 3 - $9 \mu$, espessura de 3-6; elementos fibrosos vão de curtos a longos com $1.320-1.850 \mu$ de comprimento, maioria entre $1.400-1.650 \mu$. Camadas de crescimento demarcadas por zonas de camadas fibrosas mais compacta sem presença de parênquima e ocasionalmente de poros. Máculas medulares e canais intercelulares não foram observados.

\section{Usos Comuns :}

Marcenaria, construção em geral.

Dimorphandra parviflora Spr. ex Bth. in Mart. FI. Bras., XV II : 251.

\section{Caracteres botânicos :}

Árvore de porte mediano, muito raramente excedendo a $20 \mathrm{~m}$ de altura, e relativamente freqüente nas matas de terra firme das proximidades de Manaus, provavelmente, também no interior do Estado. Ramos, pecíolos e inflorescência ferrugíneo - tomentosos. Folhas multipinadas; pinas com 8 (12) jugos; foliolos alternos, subcoriáceos, glabros na face superior, na inferior ferrugíneo pubescentes, margem em geral recurvada. Inflorescência terminal ou subterminal, densa, corimbiforme com pedunculo espesso. Flores amareladas, de cheiro desagradável, pequenas, numerosas, sésseis e efêmeras. Fruto legume, ligeiramente recurvado e espesso, curtamente estipitado na base.

\section{Habitat :}

Freqüente na mata de terra firme em solo argiloso, e ocasional na capoeira onde os indivíduos atingem menor porte.

\section{Ocorrências geográficas :}

Est. Amazonas: Muito freqüente em Manaus e arredores; municípios de Tefé e Borba.

Est. Pará: seg. Ducke (1949), em Santarém, serra de Itaituba e região das cachoeiras inferiores do Tapajós (São Luís, Flechal).

\section{DADOS GERAIS SOBRE A MADEIRA}

\section{CARACTERÍSTICAS GERAIS :}

Madeira muito pesada $\left(1,00 \mathrm{~g} / \mathrm{cm}^{3}\right)$; cerne alaranjado quando verde, passando para mar- 
Dimorphandra parviflora Benth

7

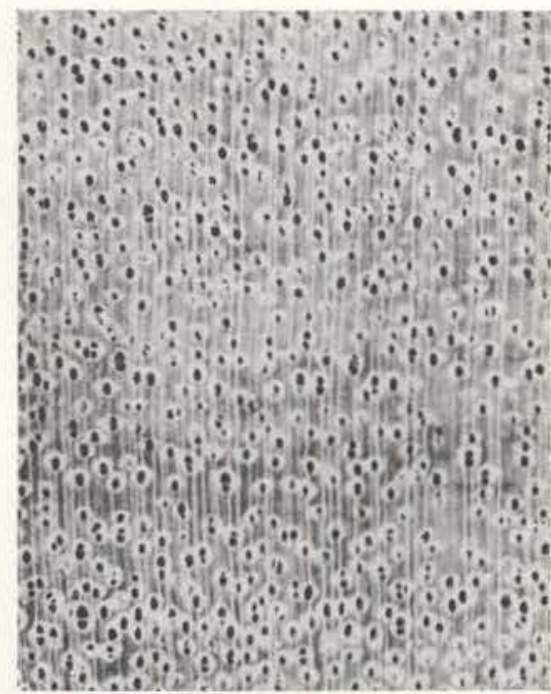

Cortz transversal (5x)

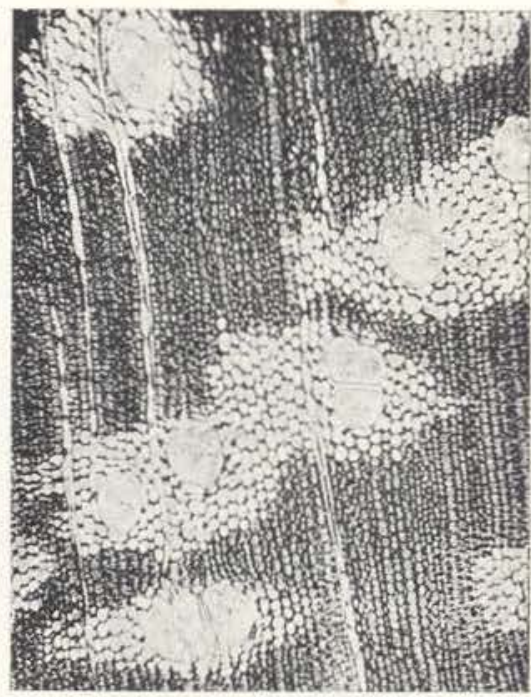

Corte transversal $(80 \mathrm{x})$

9

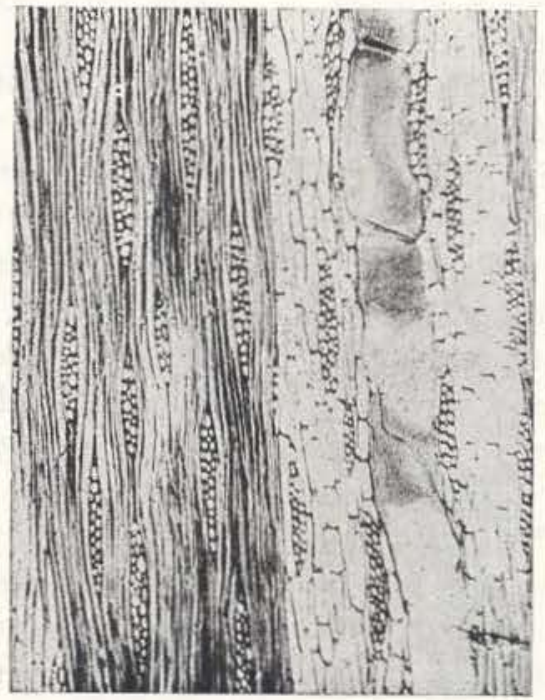

Corte tangenclal $(60 \mathrm{x})$ 
rom claro quando seco; alburno amarelo com tonalidade brilhante; grã média; textura grosseira; cheiro não pronunciado; gosto amargo. Boa de trabalhar, recebendo bom acabamento com polimento atrativo.

\section{DESCRIÇÃO MACROSCÓPICA :}

Parênquima contrastado, aliforme de aletas curtas, só visível sob lente, paravascular, com certa tendência para confluente. Poros apenas distintos a olho desarmado, médios a grandes, alguns pequenos, de pouco numerosos a numerosos, solitários, múltiplos de $2-3$, raríssimos de 4 poros, vazios, alguns obstruídos. Linhas vasculares são longas, retas, bem perceptíveis a simples vista. Raios no topo são finos, apresentando uma boa uniformidade na largura e espaçamento, só visível com ajuda de lupa; na face tangencial são irregulares, na radial são contrastados. Camadas de crescimento um tanto realçadas pelo tecido fibroso mais escuro. Máculas medulares e canais secretores não foram observados.

\section{DESCRIÇÃO MICROSCÓPICA :}

Vasos de parede média, 6-9 $\mu$, ligeiramente angulosa, secção quase circular ou ovalada, distribuição difusa; pequenos a médios, diâmetro tangencial variável de $70-130 \mu$, excepcionalmente até $150 \mu$; de muito pouco a poucos 4-10 por $\mathrm{mm}^{2}$, maioria de $6-8$; solitários predominantes $(63 \%)$, geminados $(31 \%)$, raros de 3- 4 vasos; pontuações intervasculares pequenas, guarnecidas, alternas, areoladas, abertura inclusa, placas de perfurações simples; elementns vasculares de muito curtos a longos, com uma viração de 170 - $500 \mu$ de comprimento, predominando os de 300-400 $\mu$, constituídos de apêndice em uma das extremidades e raros de lado diferente. Raios heterocelulares, irregularmente dispostos, de 1 - 4 células de largura, com predominância dos trisseriados $(64 \%)$, bisseriados $(23 \%)$ e unisseriados com apenas $(13 \%)$; altura dos raios vai de $100-400 \mu$, excepcionalmente de $60-440 \mu$ de altura, maioria está entre $210-300(55 \%)$, de $310-400(25 \%)$ e de $110-200$ $\mu$ de altura, encontramos apenas $(14 \%)$; altura em número de células ocorre de $3-19$, com mais freqüência aqueles raios de $11-19(80 \%)$ células de altura, ocasionalmente encontra-se de 2 - 20 células de altura; número de raios por milimetro linear de 4-8 com mais freqüência de $5-7(87 \%)$; pontuações radiovasculares do mesmo tipo das intervasculares. Parênquima axial paratraqueal, abundante, aliforme de aletas curtas e estreitas, formando pequenos agrupamentos de 2 ou mais poros ou mesmo confluente oblíquo. Cristais ausentes ou extremamente raros. Fibras espessura da parede média com 3-6 $\mu$, diâmetro do lúmen ocorre en tre 3-9 $\mu$, elementos fibrosos de muito curtos a curtos com um comprimento de $1.000-1.500$ $\mu$, maioria está entre $1.200-1.450 \mu$ de comprimento. Camadas de crescimento pouco definidas por zonas de camadas fibrosas.

\section{USOS COMUNS :}

Caixotaria, construção civil.

Le Cointea amazonica Ducke. In Arch. Jard. Bot. Rio de Janeiro, $3: 128.1922$.

Nomes vulgares:

BRASIL - Est. Amazonas: Paracuuba, Pracuuba (Autaz - Mirim).

Est. Pará: Pracauuba (Óbidos); p. cheirosa da várzea (Gurupá), seg. Le Cointe (1947)

\section{Caracteres botânicos:}

Árvore mediana, muito raramente atingindo grande porte, freqüente nas margens periodicamente inundaveis dos rios Amazonas e Solimões; tronco escuro profundamente sulcado no sentido longitudinal, casca escura. Ramos jovens glabros, enegrecidos. Folhas coriáceas, curto-pecioladas, freqüentemente com os lados desiguais, glabras, de margem denteada; dentículos aparentemente uniformes e ascendentes. Inflorescência em ramos solitários ou até 5 na axila das folhas caídas. Flores caducíssimas com pétalas alvas; ovário estipitado 4 (6) ovulado, densamente pubescente, estilete glabro com o ápice freqüentemente recurvado. Fruto legume sucoso, indeiscente, amarelado quando maduro, com forte odor de jenipapo (Genipa americana) INPA 17.074; sementes 1 (2) com testa pouco dura. 


\section{Lecointea amazonica Ducke}

10

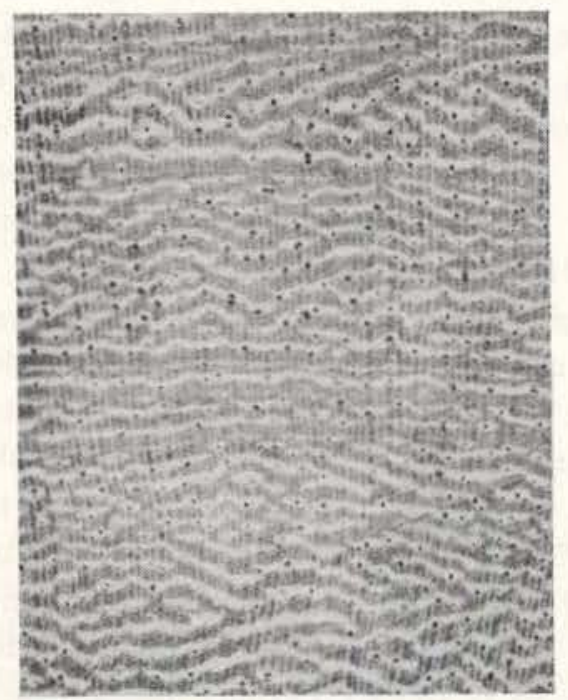

Corte transversal $(10 \mathrm{x})$
11

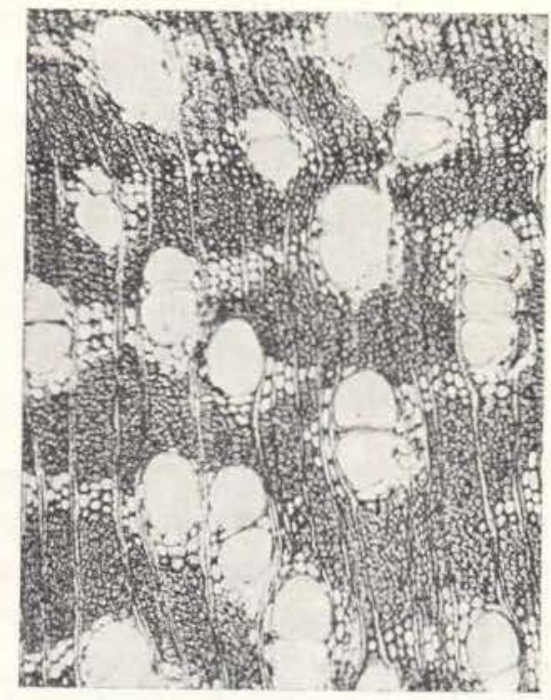

Corte transversal $(80 \mathrm{x})$

12

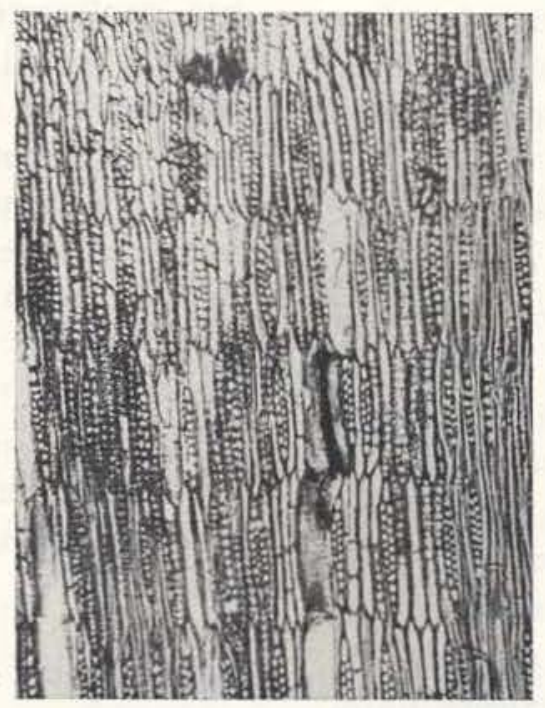

Corte tangencial (60x) 
Habitat :

Característica das matas de várzea, em solo argiloso, ocorrendo muito raramente na mata de terra firme, onde os indivíduos têm porte reduzido.

\section{Ocorrência geográfica :}

Freqüente ao longo dos rios Amazonas, Solimões e seus afluentes, e no Estado do Pará (Municípios de Óbidos, Santarém e Faro). Loureiro \& Silva (1968).

\section{DADOS GERAIS SOBRE A MADEIRA}

\section{CARACTERÍSTICAS GERAIS :}

Madeira bonita, resistente, muito pesada $\left(0,92-1,10 \mathrm{~g} / \mathrm{cm}^{3}\right)$; cerne amarelo-róseo, uniforme, escurecendo com o tempo; alburno branco-amarelado, bem demarcado do cerne; grã regular; textura média; cheiro agradável de rosa quando trabalhada ou queimada; gosto indistinto. Boa de trabalhar, recebendo acabamento esmerado, compacta, homogênea. Fornece carvão de grande poder calorífico.

\section{DESCRIÇÃO MACROSCÓPICA :}

Parênquima abundante, apenas visivel a olho nu, bem distinto sob lente, em faixas finas terminais, afastadas e confluentes que se unindo ligam os poros, partes em faixas tangenciais, parte em grupos oblíquos, apresentando-se onduladas e curtas. Poros distintos apenas com ajuda de lente, numerosos, solitários e agrupados, total ou parcialmente vazios. Linhas vasculares finas e retas. Raios no topo com uma distribuição uniforme na largura e espaçamento, são finos e numerosos, somente perceptíveis sob lente; no sentido perpendicular aos raios apresentam-se estratificados e paralelamente a estes (radial), são contrastados. Camadas de crescimento bem demarcadas por zonas fibro sas escuras delimitadas pelo parênquima terminal. Máculas medulares e canais secretores não identificados.
DESCRIÇÃO MICROSCÓPICA :

Vasos de muito pequenos a médios, de 30 - $130 \mu$ de diâmetro tangencial, maioria entre $70-100(80 \%)$, distribuicção difusa, parede com 6- $9 \mu$ de espessura; de pouco numerosos a numerosos, variando de $15-30$ vasos por $\mathrm{mm}^{2}$, maioria entre $18-25(75 \%)$; solitários predominantes $(55 \%)$, geminados $(38 \%)$, alguns múltiplos de 3 e excepcionalmente em pequenas cadeias de 4, vazios; placas de perfurações simp!es; pontuações intervasculares guarnecidas, areoladas, inclusa, alternas, $3 \mu$; elementos vasculares muito curtos $200-280 \mu$ de comprimento, maioria está na faixa de $220-250 \mu$; não observamos presença de apêndice. Raios regularmente estratificados, bisseriados predominantes $(72 \%)$, unisseriados $(25 \%)$, raríssimos trisseriados; extremamente baixos, maioria $150-170 \mu$ de altura (58\%), de $100-140(11 \%)$, de $180-200(27 \%)$, excepcionalmente ou localmente de 210-220; altura dos raios em número de células é variável de $5-13$, com predominâncias de 8 - 12 (88\%) células de altura; os raios ocorrem numa estratificação de 11-16 raios por milimetro linear, predominando os de $12-15(88 \%)$; pontuações radiovasculares do mesmo tipo das intervasculares, sendo um pouco maiores. Parênquima axial paratraqueal abundante, aliforme de expansões laterais Iongas, confluentes, formando faixas irregulares e ainda terminal de 2 - 8 células de largura, predominando as faixas com 4 - 6 células, presente também o apotraqueal escasso. Cristais abundante em longas séries de hemicristaliferas a holocristaliferas, anexadas ao parênquima. Fibras de muito curtas a curtas $860-1.100 \mu$ de comprimento, maioria ocorre na faixa de $900-1.000 \mu$. Camadas de crescimento pouco definidas, eventualmente demarcadas por zonas fibrosas de parede mais espessa. Máculas medulares e canais intercelulares não identificados.

USOS COMUNS :

Ebanisteria, construções em geral, cabos de ferramentas, suumba de flechas, obra de torno. 
Macrolobium acaciaefolium Bth. in Mart. FI Bras. XV (II) : 224.

\section{Nomes vulgares:}

BRASIL - Est. Amazonas: Arapari, A. verdadeiro (Manaus); $A$. da várzea, no interior do Estado.

Est. Pará : Faveira (Cachoeira do rio Tapajós, Ducke 1949); Fava de tambaqui, Le Cointe (1947); Arapari e Paracaxi (beira do rio Arari, Ilha de Marajó).

Est. Maranhão: Arapari.

Ter. Fed. Amapá: Arapari (Aporema, Campo Belo, INPA 12.024, MG); Raparigueira.

\section{Caracteres botânicos:}

Árvore em geral de porte mediano, em raríssimos casos com altura superior a $25 \mathrm{~m}$. Fus$t \in$ volumoso com casca castanho-acinzentada, finamente estriada. É provavelmente no gênero, a espécie mais freqüente em nossa região, tornando-se por sua elegância e beleza quando coberta de flores, cf. já se referiu Ducke (1941), "elemento de destaque na paisagem". Por essas razões, não fora as exigências de habitat para o seu desenvolvimento normal, poderia a espécie ser aconselhada para a ornamentação regional. Folíolos coin 20 (30) jugos, estreitos, ou oblongos a lineares, de ápice obtuso e base freqüentemente desigual, glabros, verde-brilhante na face superior, na inferior opaca, com nervação secundária inaparente. Inflorescência em rácemos curtos, ocasionalmente ultrapassando a $4 \mathrm{~cm}$ de comprimento, multiflora, cano-pubescente. Flores brancas, pequenas, estames Ion gos, vermelhos. Fruto legume, ovado-orbicular, curto-estipitado, lenhoso, glabro, vernicoso, castanho-amarelado (em estado seco), monoespermo, indeiscente, possibilitando assim a sua dispersão através da água.

Habitat :

Cresce espontaneamente e com relativa abundância nos lugares sujeitos a inundações temporárias, na margem dos rios, lagos e campos baixos da Amazônia.

\section{Ocorrência geográfica :}

Ocorre no Estado do Amazonas (com relativa abundância), Pará, Acre e Territórios do Amapá, Rondônia e Roraima, também no Estado de Goiás, Guianas e partes amazônicas do Peru e Colômbia - Ducke (1949).

\section{DADOS GERAIS SOBRE A MADEIRA}

\section{CARACTERÍSTICAS GERAIS :}

Madeira moderadamente pesada $(0,60-0,65$ $\mathrm{g} / \mathrm{cm}^{3}$ ); cerne castanho-avermelhado; alburno pardacento; grä geralmente direita; textura média; cheiro e gosto indistintos. Não difícil de trabalhar, recebendo acabamento atrativo, de lustre mediano, curvando-se bem.

DESCRIÇÃO MACROSCÓPICA :

Parênquima relativamente abundante, em geral do tipo paratraqueal, visivel sob lente, pouco contrastado, aliforme, abrangendo dois ou mais poros, vasicêntrico de pouca confluência, e em faixas terminais afastadas, às vezes duplas. Poros visíveis a olho desarmado, poucos, pequenos a médios, solitários, agrupados de 2 - 3 poros, ovalados, vazios. Linhas vasculares perceptíveis a simples vista, um tanto altas e retas. Raios no topo são finos e numeresos, visiveis somente com auxílio de lente, apresentando uma certa uniformidade na largura e espaçamento; na face tangencial aparecem curtos e irregularmente dispostos, na radial apenas notados a simples vista. Anéis de crescimento demarcados por zonas fibrosas mais escuras e compactas do lenho tardio, ainda por faixas concêntricas do parênquima apotraqueal concêntrico, estreito. Máculas medulares e canais secretores não identificados.

DESCRIÇÃO MICROSCÓPICA :

Vasos de secção geralmente subcircular até nitidamente oval, distribuição um tanto irregular, espessura da parede de 6-9 $\mu$, totalmente vazios; médios a grandes, diâmetro tangencial está entre 100-250 $\mu$, maioria dos casos oscilam entre a dimensão de $100-200(93 \%)$; extremamente poucos $2-6$ por $\mathrm{mm}^{2}$; solitários e múl- 
Macrolobium acaciaefolium Benth

13

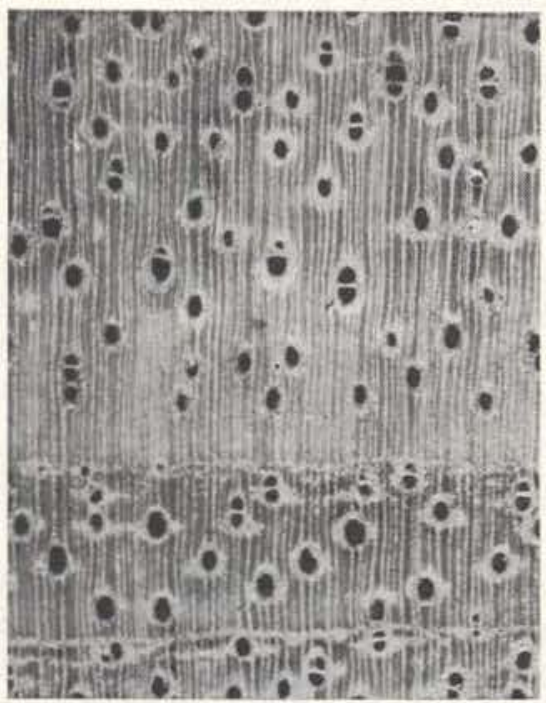

Corte transversal $(10 \mathrm{x})$
14

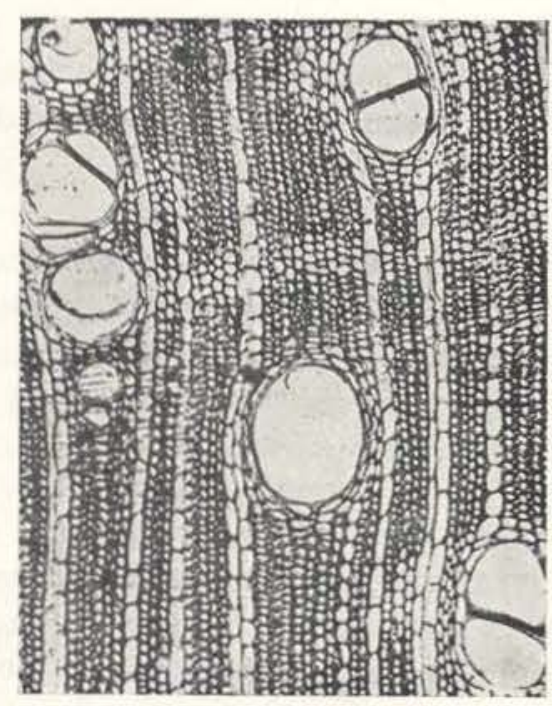

Corte transversal $(60 \mathrm{x})$

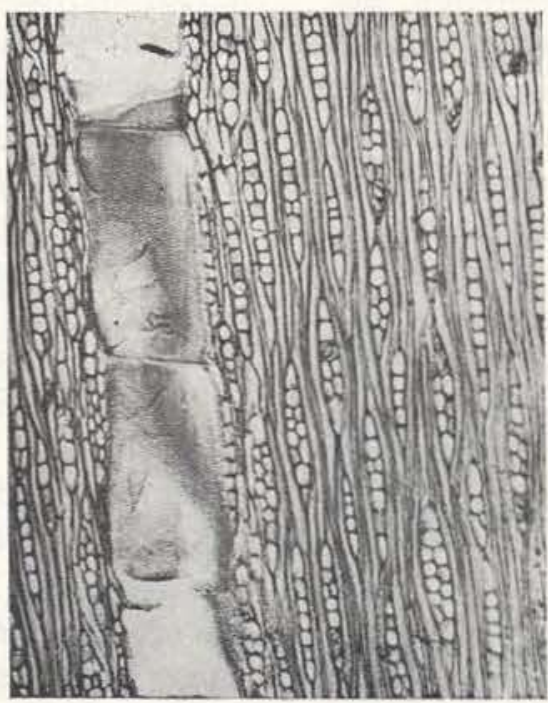

Corte tangencial $(60 \mathrm{x})$ 
tiplos $(88 \%)$, alguns agrupados de $3-4$; placas de perfurações simples; pontuações intervasculares semi-areoladas, numerosas, disposição alterna, guarnecidas de contorno circular com diâmetro de 3 - $6 \mu$; elementos vasculares curtos, de $300-500 \mu$ de comprimento, maioria ocorre entre a faixa de $350-420 \mu$, apresentando apêndice pequeno de um lado do elemento e raros de lado diferente. Raios heterogêneos, irregularmente distribuídos, de extremamente baixos, apresentando uma altura variável em $\mu$ de $150-380$, predominando os de $210-300(75 \%)$, excepcionalmente encontrando-se de $100-430 \mu$; bisseriados predominantes $(60 \%)$, unisseriados $(37 \%)$, alguns trisseriados; altura em número de células de $3-12$, sobressaindo os de $6-8$ $(61 \%)$, raramente ou localmente até 13 ; muito numerosos, maioria de $10-12$ por milímerto linear $(77 \%)$, mínimo 8 , máximo 13 raios; pontuações radiovasculares, iguais as inter, porém um pouco menores. Parênquima axial paratraqueal. aliforme de aletas curtas, às vezes longas, aparentemente circunvascular, ainda em linhas ou pequenas faixas estreitas, terminais, afastadas. Cristais presentes, observados em todos os cortes, mais freqüente no radial. Fibras de pontuações areoladas com 3-6 $\mu$; de muito curtas a longas, oscilando de $1.000-1.820 \mu$ de comprimento, predominando aquelas de $1.300-1.600$ $\mu$, lúmen de $9-12 \mu$, a sua espessura não ultrapassa $3 \mu$. Camadas de crescimento aparentemente demarcadas por faixas de parênquima terminal. Máculas medulares e canais intercelulares não observamos.

\section{Usos comuns :}

Carpintaria, marcenaria, caixas, celulose para papel, tábuas de boa qualidade. É empregada na fabricação de móveis vergados. É bem flexível, tomando formas variadas.

\section{SUMMARY}

In this paper a contribution to the dendrological hnowledge of the amazonian species of the family Leguminosae, in given by the authors, by including the botanical description, geographical distribution habitat and anatomical description of the woods of the following species: Hymenaea parvifolia, Crudia amazonica, Dimorphandra parviflora, Lecointea amazonica and Macrolobium acaciaefolium. 15 illustrations of the woods described are included in this psper.

\section{BIBLIOGRAFIA CITADA}

BRASIL. SUPERINTENDÊNCIA DO DESENVOLVIMENTO DA AMAZÔNIA

1969 - Algumas informações úteis sôbre madeiras da Amazônia. 50 espécies de árvores possivelmen. te apropriadas para lâminas faqueadas. Belém, SUDAM, p. 20 .

Chattaway, M. M.

1932 - Proposed Standards for numerical values used in discribing wood. Trop. Woods, New Haven, 29:20-28.

DUCKE, A.

1935 - As espécies brasileiras de Jatahy, Jutahy ot Jatobá (gênero Hymenaea L., leguminosas caesalpiniaceas). Anais Acad. Bras. Cienc, , Ric de Janeiro, 7(3):204-211.

1941 - As leguminosas da Amazônia brasileira. Notas sôbre a flora neotrópica. II. Bol. Técn. Inst. Agron. Norte, Belém, 18: 79, 84, 88, 97, 145.

Le CoInte, Paul

1947 - Amazônia Brasileira. III - Árvores e plantas úteis (Indigenas $e$ aclimadas). 2. ed. São Paulo, Ed. Nacional. p. $46,47,193,250,379$ (Brasiliana, série 5.a, v. 251).

LOUREIro, A. A. \& SILVA, M. F. DA

1968 - Catálogo das madeiras da Amazônia. Belém, SUDAM. v. 1, p. $355,356,361,362$.

Milanez, F. Romano \& Bastos, A. de Miranda

1960 - Glossário dos têrmos técnicos usados em anatomia de madeiras. Anu. Bras. Econ. Flor. Rio de Janeiro, 12(12):1-27.

RECORD, S. J. \& HESS, R. W.

1949 - Timbers of the New World. New Haven, Yale Univ. press. p. 251, 291. 